\title{
Whole-Exome Sequencing of Matched Primary and Metastatic Papillary Thyroid Cancer
}

\author{
Tariq Masoodi,, ${ }^{1, *}$ Abdul K. Siraj,, ${ }^{1, *}$ Sarah Siraj,, Saud Azam,, Zeeshan Qadri, \\ Wafaa N. Albalawy, ${ }^{1}$ Sandeep Kumar Parvathareddy, ${ }^{1}$ Saif S. Al-Sobhi, ${ }^{2}$ Fouad Al-Dayel, ${ }^{3}$ \\ Fowzan S. Alkuraya, ${ }^{4,5}$ and Khawla S. Al-Kuraya ${ }^{1}$
}

Background: Distant metastasis is a rare occurrence in thyroid cancer, and it can be associated with poor prognosis. The genomic repertoires of various solid malignancies have previously been reported but remain underexplored in metastatic papillary thyroid cancer (PTC). Furthermore, whether distant metastases harbor distinct genetic alterations beyond those observed in primary tumors is unknown.

Methods: We performed whole-exome sequencing on 14 matched distant metastases, primary PTC tumors, and normal tissues. Point mutations, copy number alterations, cancer cell fractions, and mutational signatures were defined using the state-of-the-art bioinformatics methods. All likely deleterious variants were validated by orthogonal methods.

Results: Genomic differences were observed between primary and distant metastatic deposits, with a median of $62 \%$ (range 21-92\%) of somatic mutations detected in metastatic tissues, but absent from the corresponding primary tumor sample. Mutations in known driver genes including $B R A F, N R A S$, and $H R A S$ were shared and preferentially clonal in both sites. However, likely deleterious variants affecting DNA methylation and transcriptional repression signaling genes including SIN3A, RBBPI, and CHD4 were found to be restricted in the metastatic lesions. Moreover, a mutational signature shift was observed between the mutations that are specific or enriched in the metastatic and primary lesions.

Conclusions: Primary PTC and distant metastases differ in their range of somatic alterations. Genomic analysis of distant metastases provides an opportunity to identify potentially clinically informative alterations not detected in primary tumors, which might influence decisions for personalized therapy in PTC patients with distant metastasis.

Keywords: exome sequencing, papillary thyroid cancer, distant metastasis, DNA methylation

\section{Introduction}

G LOBAL INCIDENCE RATES OF THYROID CANCER have rapidly increased in recent years (1). In Saudi Arabia, thyroid cancer accounts for $11.5 \%$ of all cancers and is the second most common cancer affecting Saudi females after breast cancer (2). Among different histological subtypes of thyroid cancer, papillary thyroid cancer (PTC) is the most common cancer, accounting for up to $80 \%$ of all newly diagnosed thyroid carcinoma cases (3).

Although metastasis to regional or local lymph nodes is common, distant metastasis is a less frequent event and oc- curs in less than $6 \%$ of patients (4-7). Furthermore, despite the usually favorable prognosis of PTC following appropriate treatment $(8,9)$, distant metastasis is the most common cause of thyroid cancer-related mortality $(10,11)$. Surgery and radioiodine therapy are the major treatment modalities in patients with ${ }^{131}$ I uptake $(12,13)$, including patients demonstrating progressive disease and distant metastasis. Therefore, identifying new molecular targets and proposing new treatment modalities are clearly needed for patients with distant metastasis. There is a considerable lack of molecular profiling in metastatic PTC, where focus has typically been limited to primary thyroid lesions (14-16).

\footnotetext{
${ }^{1}$ Human Cancer Genomic Research; Departments of ${ }^{2}$ Surgery, ${ }^{3}$ Pathology, and ${ }^{4}$ Genetics, King Faisal Specialist Hospital and Research Centre, Riyadh, Saudi Arabia.

${ }^{5}$ Department of Anatomy and Cell Biology, College of Medicine, Alfaisal University, Riyadh, Saudi Arabia.

*These authors contributed equally to this work.

(C) Tariq Masoodi et al., 2019; Published by Mary Ann Liebert, Inc. This Open Access article is distributed under the terms of the Creative Commons Attribution Noncommercial License (http://creativecommons.org/licenses/by-nc/4.0/) which permits any noncommercial use, distribution, and reproduction in any medium, provided the original author(s) and the source are cited.
} 
Exome sequencing of solid tumors has been previously used to investigate the clonal relationship between primary tumors and metastasis in several cancers, including breast, colorectal, endometrial, urothelial, and hepatocellular carcinomas (17-25), but has yet to be explored in thyroid cancer. Comparing distant metastasis with their corresponding primary tumor from PTC patients could uncover differences in their somatic genetic alterations. This can be relevant to a precision medicine approach in the clinical management of PTC patients with metastasis.

In this study, we undertook genomic sequence analysis of primary PTC and their distant metastatic deposits (lung, bone, kidney, and brain), in patients who presented with metastatic disease that was present at initial diagnosis before therapy, or metastases that developed after receiving initial therapy. Our aim was to determine differences in the repertoire of somatic mutations, copy number alterations (CNAs), and mutational signatures between primary PTC and their distant metastases.

\section{Methods \\ Clinical samples}

We performed whole-exome sequencing (WES) on 42 trios of patient-matched distant metastases, primary tumors, and normal samples, collected during the course of clinical care (e.g., for diagnosis, symptoms control, or restaging) from 14 patients at the King Faisal Specialist Hospital and Research Centre from the Department of Pathology. Nine of these patients presented with metastasis at initial diagnosis before therapy (cases: 1, 3, 4, 6, 7, 8, 10, 12, and 14), while five (cases: 2, 5, 9, 11, and 13) developed distant metastasis after a median of 37 months post-therapy (surgery followed by radioactive iodine). The clinicopathological details of these patients are summarized in Supplementary Table S1. This study was approved by the Research Advisory Council (RAC) of the hospital, under project RAC No. 2110031.

\section{DNA extraction and WES}

DNA was extracted from formalin-fixed paraffinembedded tissue blocks by performing punches in the corresponding tissue areas and extraction with the Gentra DNA isolation kit (Gentra, Minneapolis, MN) following the manufacturer's recommendations. WES was executed using SureSelectXT Target Enrichment (Agilent) on Illumina NovaSeq 6000. Sequencing reads were aligned to the human reference genome hg19 using Burrows-Wheeler Aligner v0.7.15 (26) algorithm with default settings, followed by local realignment and polymerase chain reaction duplicate marking via Picard tools (v1.119). Base-quality recalibration and calculation of coverage metrics were performed with GATK v3.8.0 (27). All cases passed internal quality control and quality matrix. By means of tumor-normal bam files, somatic single nucleotide variations (SNVs) were identified using MuTect v1.1.7 (28), while somatic small insertions and deletions (indels) were identified using VarScan v2.3.9 (29). Identified variants were annotated using ANNOVAR (30). In addition to passing the standard MuTect and VarScan filters, variants presenting with the following features were excluded: common single nucleotide polymorphisms (SNPs) with a minor allele frequency of $>0.05$, as documented in dbSNP, the National Heart, Lung, and Blood Institute exome sequencing project, 1000 Genomes, and in our in-house data from exome sequencing of $\sim 700$ normal samples; noncoding region variants; and variants in repetitive regions. Mutations were also manually checked using the Integrated Genomics Viewer v2.4.10 to filter out false positives. All potentially deleterious variants were validated by Sanger sequencing as previously described (31).

\section{Gene copy number profiling and cancer cell fraction}

FACETS v0.5.13 (32) was used to determine CNAs and regions of loss of heterozygosity ( $\mathrm{LOH})$, while outputs generated by MuTect and VarScan were utilized to calculate mean allelic frequency. CNA and SNV data were analyzed by ABSOLUTE v1.0.6 (33) to define the integer copy number, tumor purity, and cancer cell fractions (CCFs). CNAs were further defined as gains, amplifications, or homozygous deletions, in relation to the average ploidy of all samples from a given patient using the modal copy number for each segment from ABSOLUTE. Copy number segments with a modal copy number greater than the average sample ploidy +1 or average sample ploidy +3 were considered gains and amplifications, respectively; while copy number segments with a modal copy number less than the average ploidy -1 were classified as losses, and modal copy numbers of 0 as homozygous deletions. CCF estimates for amplifications were disregarded as it increases exponentially with the number of absolute copy numbers.

\section{Defining pathogenicity}

To delineate the potential functional effect of the generated missense SNVs, different algorithms were used such as MutationTaster (34), CHASM (35), and FATHMM (36) for variant classification. Missense variants classified as nondeleterious by MutationTaster and CHASM (thyroid) were considered likely passengers. The missense variants predicted to be "driver" and/or "cancer" by CHASM (thyroid) and/or FATHMM, respectively, were classified as likely pathogenic. Neutral inframe indels established using MutationTaster and PROVEAN (37) were considered likely passengers. Inframe and frameshift indels, splice site, and nonsense mutations were considered likely pathogenic if these mutations were associated with loss of wild-type allele (i.e., LOH) or affected haploinsufficiency genes (38). SNVs occurring in hot spot residues (39) were also considered likely pathogenic. Cancer genes were annotated based on previously published studies (40-42). All mutations not defined as potentially pathogenic or likely passenger mutations were classified as indeterminate pathogenic.

\section{Classification and enrichment of mutations in primary and metastatic lesions}

Mutations specific to metastatic lesions were defined as those present in metastatic biopsy, but absent in the corresponding primary tumor, whereas mutations enriched in the metastatic lesion were defined as those exhibiting a minimum $20 \%$ increase in metastatic CCF compared with the primary tumor. The opposite was applied for mutations specific to and enriched in the primary tumor. 
Analysis of pathways associated with the metastatic process

Prospective pathways associated with the metastatic process were identified using Ingenuity Pathway Analysis (IPA) and g:Profiler (43) — by analyzing genes with likely pathogenic mutations specific to and/or enriched in the metastatic lesion, including those associated with $\mathrm{LOH}$ in metastasis but not associated with $\mathrm{LOH}$ in the matched primary tumor.

\section{Mutational signatures}

Mutational signatures were predicted using the deconstructSigs package (44) and illustrated according to the 96 substitution classification defined by the substitution classes $(\mathrm{C}>\mathrm{A}, \mathrm{C}>\mathrm{G}, \mathrm{C}>\mathrm{T}, \mathrm{T}>\mathrm{A}, \mathrm{T}>\mathrm{C}$, and $\mathrm{T}>\mathrm{G}$ bins). The signatures were compared with 21 mutational signatures previously reported in different cancer types (45).

\section{Statistical analyses}

All statistical analyses were executed in IBM SPSS Statistics (v.21). Mann-Whitney U and Fisher's exact tests were utilized to compare continuous and categorical variables, respectively. Spearman's rank correlation tests were used to determine associations. All statistical tests were two-tailed, where $p<0.05$ was considered statistically significant.

\section{Results}

\section{Genetic heterogeneity in primary PTC and distant metastatic tissue}

All primary tumors were surgically resected before the administration of any therapeutic regimen, followed by either the resection of therapy-naive metastatic tumor or posttherapy metastatic tumor. Hence, "treatment-naive" and "post-therapy" only refers to metastatic tumors, where nine treatment-naive and five post-therapy PTC patients with their corresponding treatment-naive primary tumors of different histological subtypes were tested. We first sought to determine whether the repertoire of somatic genetic alterations in biopsies of primary tumors and their respective metastases (bone, $n=6$; lung, $n=2$; and brain, $n=1$ ) in treatment-naive patients would differ from biopsies of primary tumors and their respective metastases (bone, $n=3$; kidney, $n=1$; and lung, $n=1$ ) after receiving systemic ${ }^{131}$ I therapy. WES was performed to a median depth of 169x (range 147x-198x) in primary biopsies, $167 x$ (range $143 x-185 x$ ) in metastases, and 173x (range 139x-517x) in matched normal tissues. The analysis revealed the presence of 356 primary and 351 metastatic somatic mutations. Interestingly, the mutation burden showed no difference between treatment-naive and posttherapy biopsies with the median number of mutations being 24.5 (range 3-49) in naive and 24.5 (range 10-61) in post-therapy samples $(p=0.724)$ (Fig. 1A). However, we observed a difference in hotspot mitogen-activated protein (MAP)-kinase mutations between treatment-naive and posttreatment metastases. A higher proportion of NRAS-mutant cases were observed with $55.5 \%$ found in treatment-naive metastatic tumors compared with only $20 \%$ found in posttreatment metastatic tumors. $B R A F$ mutations were observed only in post-therapy metastases $(14 \%)$. No significant association was noted between number of mutations and clini- copathological parameters such as age, stage, or histological subtype (Supplementary Table S2).

Mutations with a high likelihood of being pathogenic (31 mutations in primary and 36 in metastasis) were validated by Sanger sequencing, confirming $24(77.4 \%)$ and 32 (89\%) mutations in primary and metastatic deposits, respectively. We compared the range of mutations detected in the primary and metastatic lesions from each patient, which revealed a median of $41 \%$ (range $8-79 \%$ ) of somatic mutations in common (Fig. 1B). Importantly, however, noticeable heterogeneity was observed with a median of 55\% (38-90\%) and a median of $62 \%(21-92 \%)$ of mutations restricted to the primary tumor and the metastasis, respectively (Fig. 1B). Furthermore, a median of $39 \%$ (range 6-61\%) and $31 \%$ (range 5-50\%) variant allele frequency (VAF) was observed for the somatic mutations found in the primary and metastasis, respectively (Supplementary Fig. S1).

\section{Distinct repertoire of genetic alterations in primary PTC and metastatic tissue}

Previous genomic landscaping studies, including The Cancer Genome Atlas (TCGA), have only identified hotspot mutations or cancer genes in primary PTC tumors, but not in metastatic tissues. Therefore, our study focused on analyzing biopsies of primary PTC and distant metastases to compare the array of somatic mutations. Previously, TERT promoter mutations, in isolation and/or in combination with other driver mutations such as $B R A F^{V 600 E}$, have been shown to play an important role in the development of a more aggressive phenotype and the development of metastases (4648). The limitation of our exome sequencing approach limits the analyses to exonic mutations, not covering intronic or other regions. This prompted us to complement our study by analyzing the samples for the presence of TERT promoter mutations via Sanger sequencing in both primary PTC and their corresponding metastatic tumors. We found $50 \%$ of primary and $64.3 \%$ of metastatic tissues harboring a TERT $228 \mathrm{C}>\mathrm{T}$ mutation $(p=0.45428)$, of which $22.2 \%$ of metastases also harbored BRAF mutations $(p=0.7764)$. The absence of significant difference in TERT promoter mutations between primary tumor and metastasis may be due to the limited cohort involved in this study to highlight the role of TERT mutations, which has been previously identified in large studies on advanced thyroid carcinomas (46-49).

We identified a median of 2 (range $0-4$ ) likely pathogenic mutations per case (primary and/or metastasis), including a median of 1 (range 0-3) likely pathogenic mutation in cancer genes (Fig. 2 and Supplementary Fig. S2). Ten cases harbored a single hotspot mutation each, eight of which were shared between primary and metastasis, namely $N R A S^{Q 61 R}$ (five cases), BRAF $F^{V 600 E}$ (two cases), and $H R A S^{Q 61 R}$ (one case). Moreover, NRAS and HRAS ${ }^{Q 61 K}$ mutations were found restricted to two cases of metastatic PTC. Similarly, $T P 53^{R 342^{*}}$ mutation was found restricted in a single case of primary PTC, whereasTP53 $3^{R 248 W}$ was found restricted in a single case of metastatic PTC (Supplementary Table S3). Driver mutations tend to be clonal, that is, present in virtually $100 \%$ tumor cells $(50,51)$. Among all likely pathogenic mutations affecting cancer genes, 20/29 (69\%) were found in biopsies of both the primary tumor and the metastases, of which 16/29 (55\%) were clonal in both (Fig. 3A, B). All 


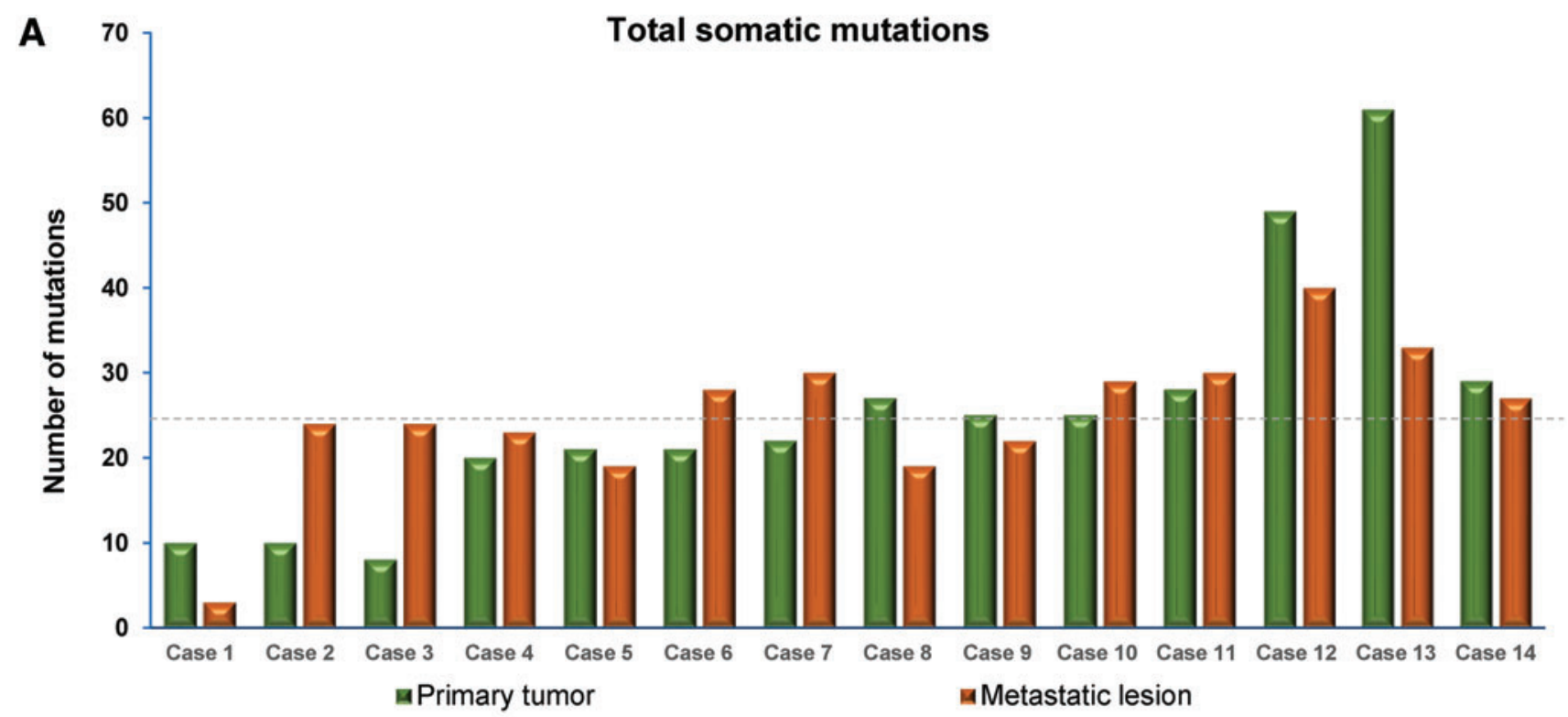

B
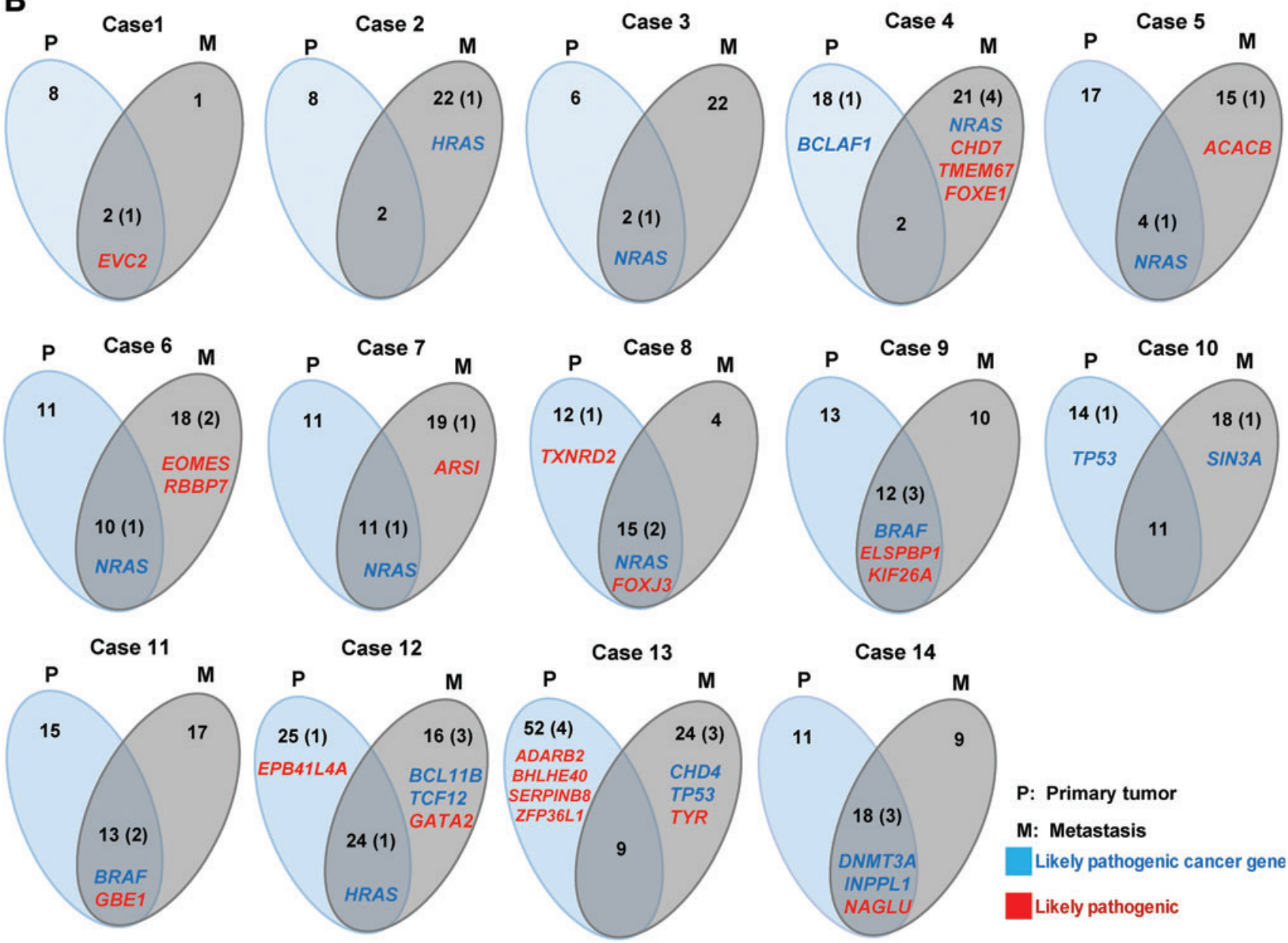

\section{P: Primary tumor}

M: Metastasis

Likely pathogenic cancer gene

Likely pathogenic

FIG. 1. Heterogeneity and somatic mutations specific to primary, metastatic tumors, and shared between both lesions. (A) Number of somatic mutations identified in primary tumors and metastatic lesions. The dashed line shows a shared median of 24.5 mutations in both the primary tumors and the metastatic lesions. (B) Venn diagrams demonstrate the number of somatic mutations and likely pathogenic mutations specific to the primary tumor, metastases, and mutations present in both lesions. The number of likely pathogenic mutations is shown in parenthesis. Labeled genes with likely pathogenic mutations in noncancer genes are colored red, while those affecting cancer genes are colored blue. Color images are available online. 


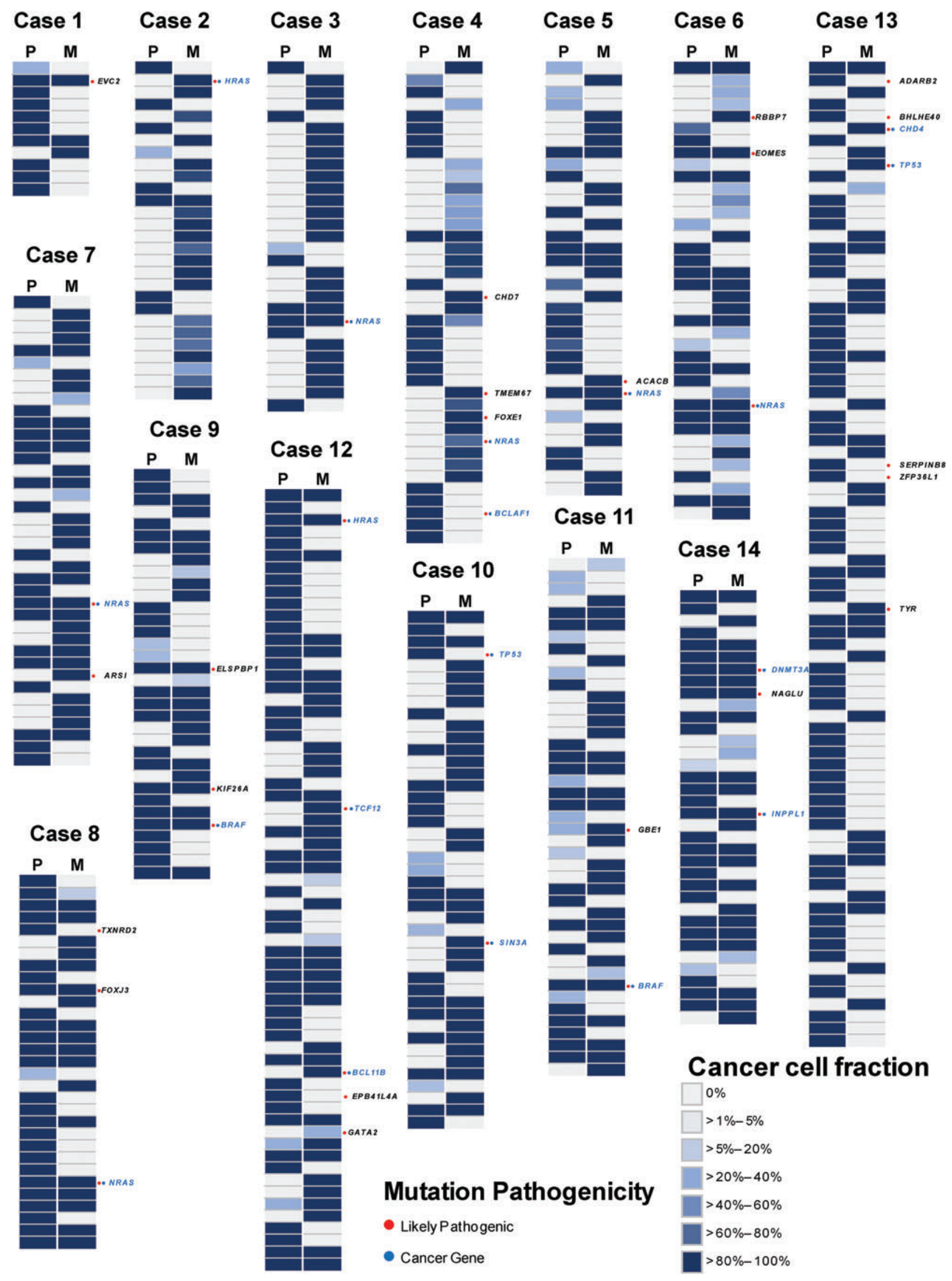

FIG. 2. Genetic repertoire of somatic mutations in primary and metastatic lesions. Heat maps show the CCF of somatic mutations demonstrated by the ABSOLUTE algorithm with their presence (blue, see color key for the CCF percentage) or absence (light gray) in the primary and metastatic deposits. Likely pathogenic mutations are indicated by red circles, and the affected genes are shown for each lesion. Likely pathogenic mutations affecting cancer genes are indicated by blue circles in each lesion, labeled in blue. CCF, cancer cell fraction. Color images are available online. 
A

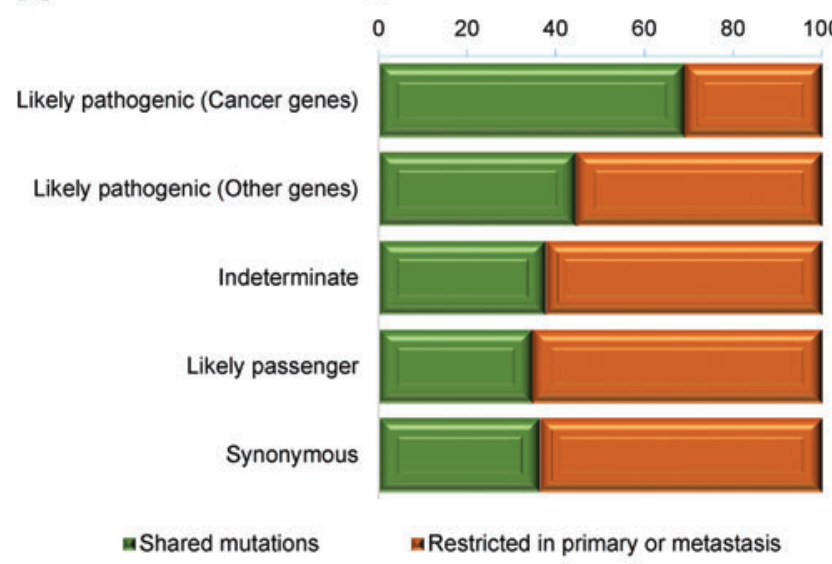

B

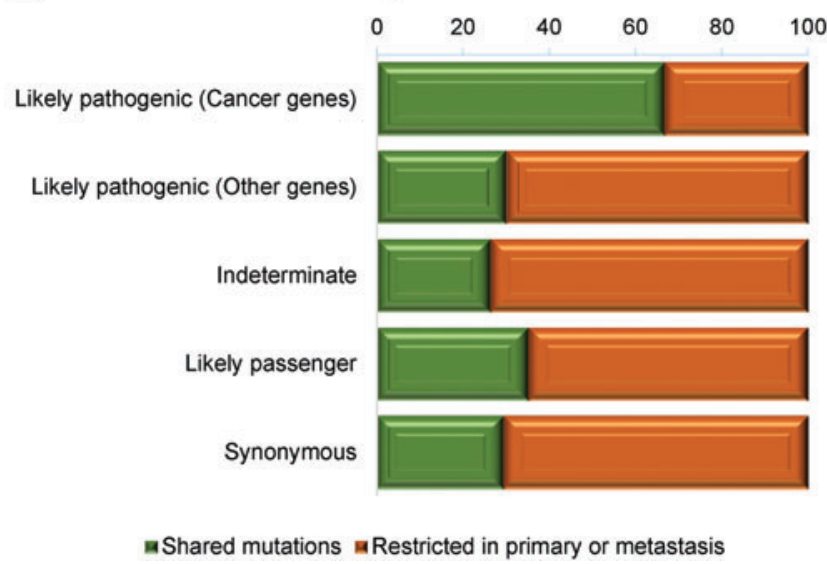

FIG. 3. Clonality in primary and metastatic lesions of papillary thyroid carcinoma. (A) Figure showing the distribution of mutations shared in the category of likely pathogenic (cancer genes), likely pathogenic (other genes), indeterminate pathogenicity, likely passenger, and synonymous mutations between primary and metastatic lesions. (B) Figure displaying the distribution of clonal mutations shared in the category of likely pathogenic (cancer genes), likely pathogenic (other genes), indeterminate pathogenicity, likely passenger, and synonymous mutations between primary and metastatic lesions. Color images are available online.

BRAF $(n=2), H R A S(n=1)$, and three cases of NRAS mutations were clonal in both biopsies. We also identified clonal mutations that are likely pathogenic, affecting the cancer genes DNMT3A and INPPL1 in a single pair of a primary tumor with its corresponding metastasis (Supplementary Table S3).

Despite limited heterogeneity in the repertoire of hotspot mutations or mutations affecting known cancer genes between primary tumors and their respective metastases, two cases presented likely pathogenic mutations affecting cancer genes restricted to metastatic lesions, namely $\mathrm{CHD} 4$ (case 13) and SIN3A (case 10) - neither of which was associated with LOH (Fig. 2). Notably, these mutations were not identified in the primary tumors even with a second anatomically distinct biopsy (Supplementary Table S4).

Concurring with the hypothesis that heterogeneity would preferentially affect passenger alterations (52), we found that mutations of indeterminate pathogenicity, likely passenger and synonymous mutations, were less frequently shared between primary and metastasis comparing to the likely pathogenic mutations in cancer genes $(37.6 \%, 34.7 \%$, and $36.4 \%$ vs. $69 \%$ and $p=0.0010, p=0.0006$, and $p=0.0008$, respectively) (Fisher's exact test; Fig. 3A, B). Interestingly, the likely pathogenic mutations (affecting a cancer gene) were more frequently synchronously present or clonal in biopsies of both lesions than indeterminate/likely passenger/synonymous mutations $(69 \%$ vs. $36.5 \%$ and $55.2 \%$ vs. $21 \%$, $p=0.0004$ and $p<0.0001$, respectively) (Fisher's exact test; Fig. 3A, B).

Copy number analysis indicated sharing of CNAs in $42 \%$ (22/52) of focal amplifications and homozygous deletions in both lesions, including amplifications affecting AKT1 (case 14), CARD11 (case 14), and BAPl (case 4). A biallelic deletion of the $S H C B P 1$ gene was observed in a single case (case 1); it was shared between the primary tumor and its metastasis (Fig. 4, Supplementary Fig. S3, and Supplementary Table S5). Noticeable differences between the primary tumor and the metastasis were observed with 7.4\% (2/27) and
$55.6 \%(15 / 27)$ amplifications, and $36 \%(9 / 25)$ and $16 \%$ (4/25) biallelic deletions specific for the primary and metastatic lesions, respectively (Supplementary Table S6).

\section{Pathway analysis of genes restricted to metastases}

In seven cases, likely pathogenic mutations were found restricted to the metastasis, affecting the $A C A C B, C H D 4$, EOMES, FOXE1, GATA2, HRAS, NRAS, RBBP7, SIN3A, TMEM67, TP53, and TYR genes (Supplementary Table S4). The mutations in these genes were absent in second anatomically distinct biopsies. These genes were investigated for the potential association with specific biological pathways. Using IPA, genes with likely pathogenic mutations specific to or enriched in metastasis demonstrated that DNA Methylation Pathway genes were significantly associated with the metastatic process $(p<0.0001$; Fig. 5 and Supplementary Table S7). Genes restricted to the DNA Methylation Pathway were found in three cases, including CHD4 (case 13), SIN3A (case 10), and $R B B P 7$ (case 6), all of which were completely absent in the two distinct primary biopsies. A further three genes (NRAS, HRAS, and TP53), showing greater than $1 \%$ frequency in primary thyroid cancer in TCGA, were filtered out, and the remaining nine genes were analyzed for pathway association. Remarkably, DNA Methylation Pathway remained the prime candidate in both IPA and $\mathrm{g}$ :Profiler $(p<0.0001$ and 0.0269$)$.

\section{Evolutionary dynamics of somatic mutations and CNAs}

To explore evolutionary patterns of somatic SNVs and CNAs, the ABSOLUTE algorithm was employed to calculate the CCF of SNVs and CNAs. A median of 23\% (range 4$60 \%$ ) and $40 \%$ (range $0-65 \%$ ) of subclonal SNVs were found in primary and metastatic tumors, respectively (Fig. 6 and Supplementary Fig. S4). Overall, no significant difference was observed in the mutation burden of subclonal mutations between primary and metastatic lesions $(p=0.265$, Mann-Whitney U test), although we note that a nominally 
FIG. 4. CNAs in primary and metastatic deposits. Figure demonstrates CNAs between primary and metastatic lesions highlighted with different color keys (blue: deletion, light blue: loss; white: neutral; light red: gain; red: amplification). CNAs, copy number alterations. Color images are available online.

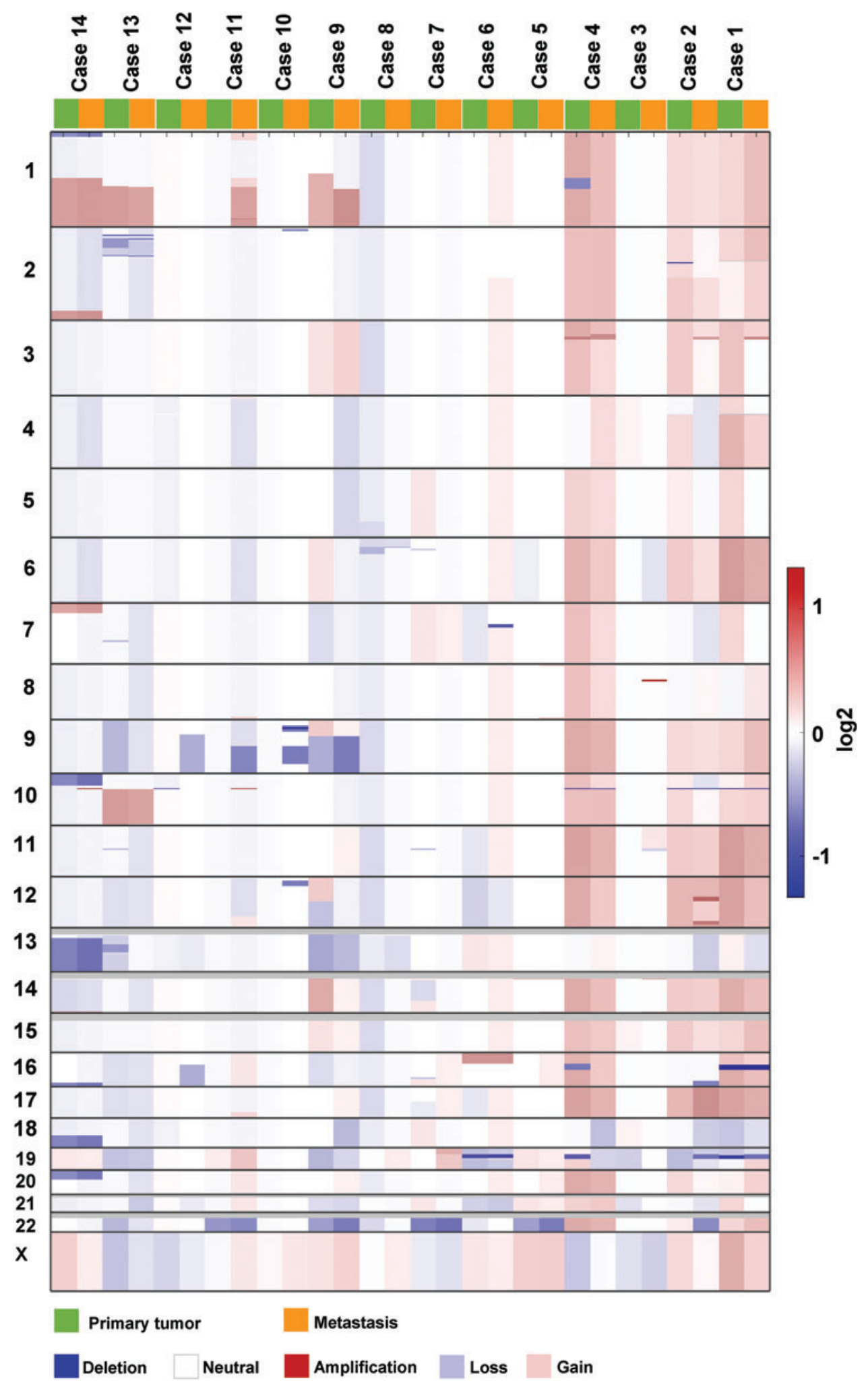

significant difference was observed in $12 / 14$ cases ( $p=0.039$, Mann-Whitney U test). Very limited heterogeneity was observed for CNAs (excluding amplifications; see the Methods section), with a median of $87 \%$ (range 29-100\%) and $83 \%$ (30-100\%) found to be clonal in the primary and the metastatic tissues, respectively (Fig. 6). No significant difference or as- sociation was observed between the proportion of subclonal mutations or of subclonal CNAs within primary-metastasis pairs (all $p>0.05$, Mann-Whitney U and Spearman's correlation tests). Furthermore, no significant difference or association was observed between the VAFs of primary and the metastatic samples $(p>0.05$, Mann-Whitney $U$ and 

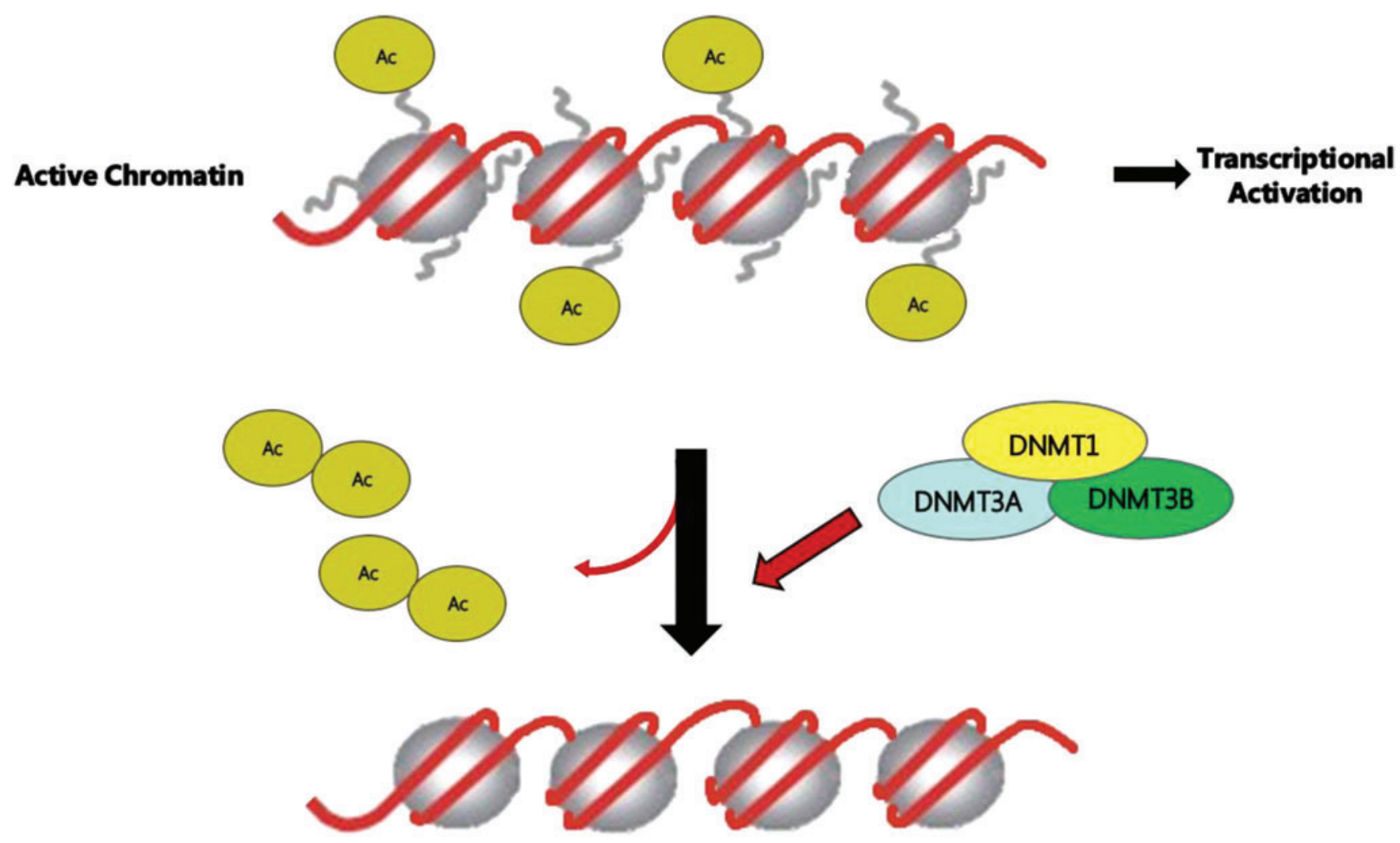

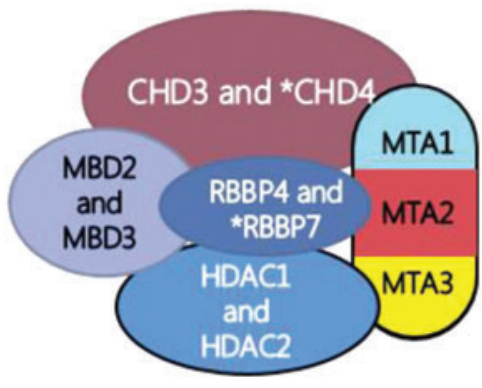

NuRD Complex

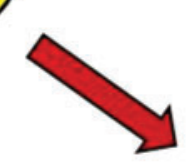

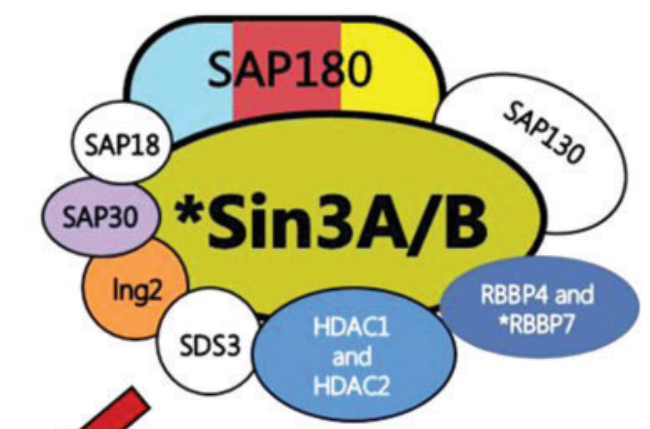

Sin3 Complex

\section{Inactive Chromatin}
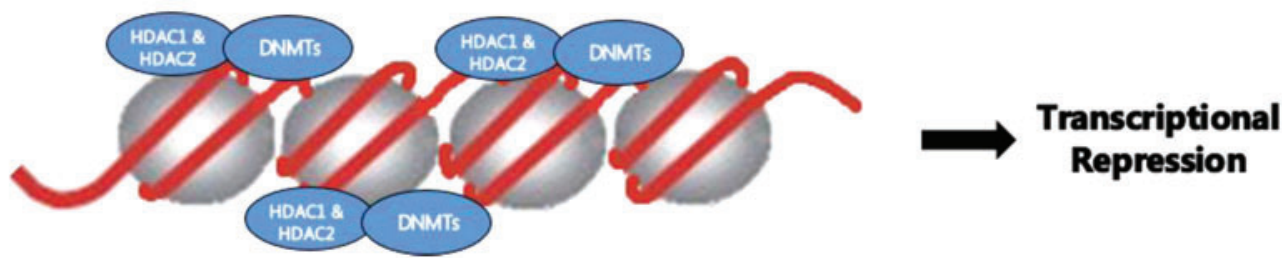

FIG. 5. Likely pathogenic mutations restricted in the metastases affect DNA methylation and transcriptional repression signaling pathway. Figure demonstrating the mechanism of genes involved in DNA methylation and repression signaling. The asterisk indicates mutated genes restricted to metastasis in the CHD4 and RBBP7 genes of the NuRD complex and SIN3A of the Sin3 complex. Color images are available online. 

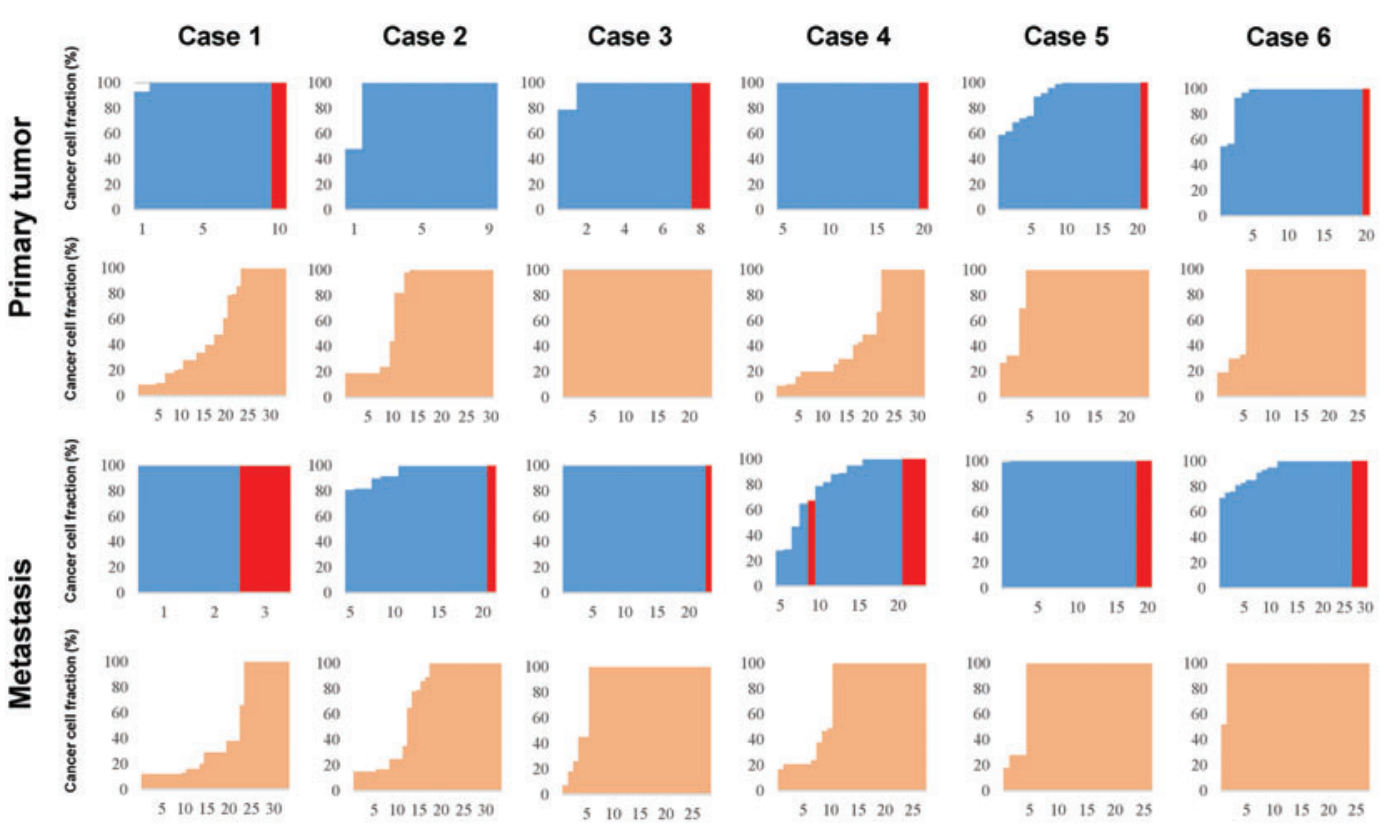

Case 7
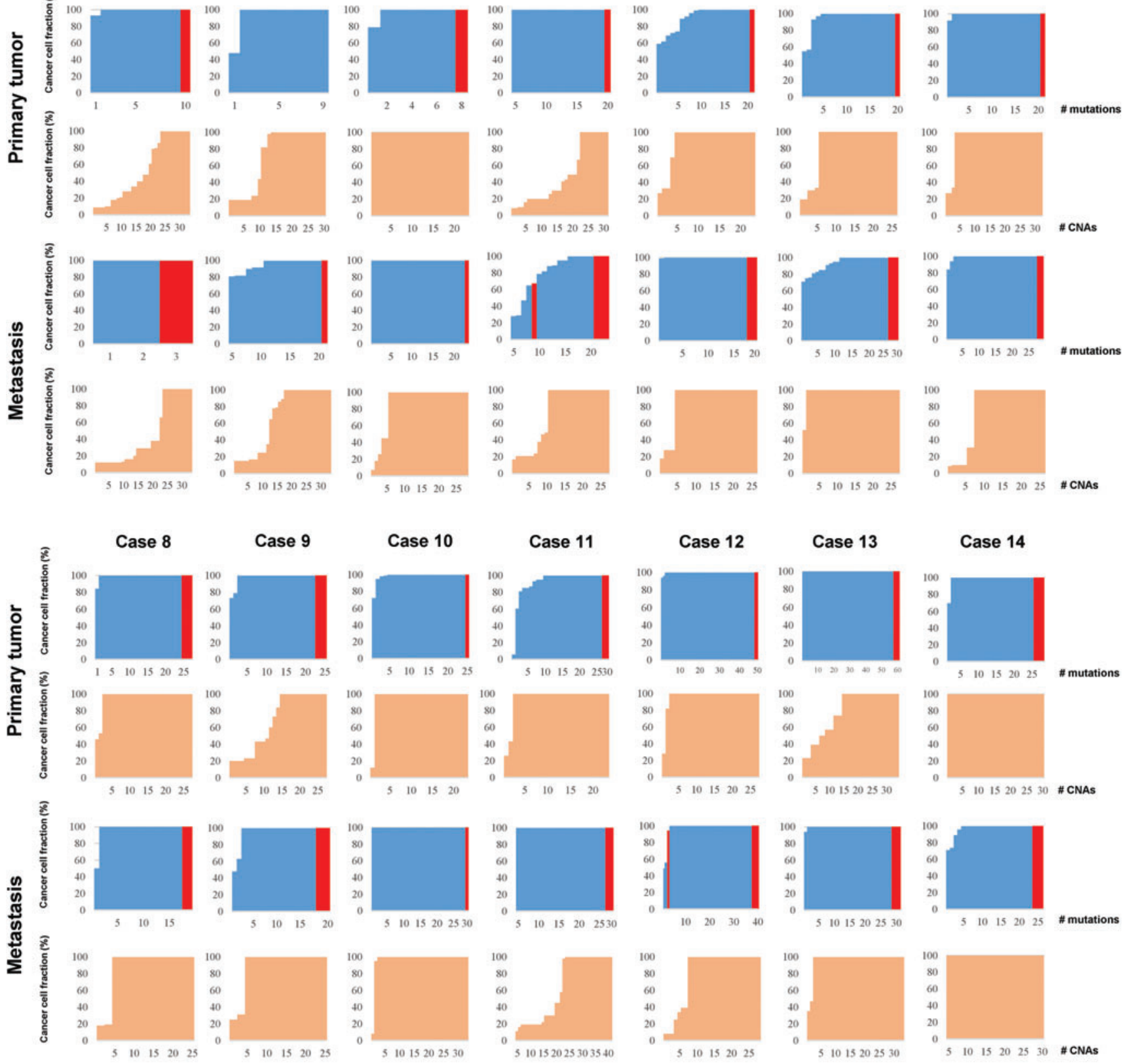

\section{Case 14}
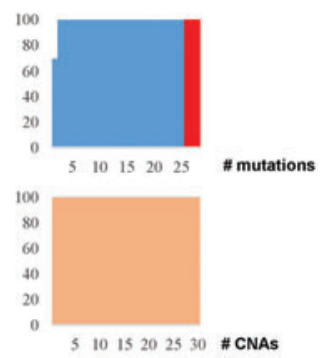

\section{Types of genetic alteration}

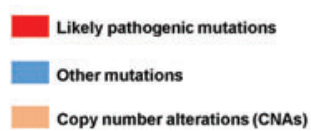

FIG. 6. Dynamics of somatic mutations and CNAs. The figure shows the CCFs of the somatic mutations (red and blue) and of the CNAs (orange, excluding amplifications; see the Methods section). CCFs of the somatic mutations and the CNAs are sorted in increasing order. Color images are available online.

Spearman's correlation tests). A proportion analysis of subclonal mutations and CNAs revealed no difference or correlation between different clinicopathological characteristics—-such as treatment (naive and post-therapy), metastatic site biopsied (bone vs. lung), histological subtype (follicular vs. tall cell), age ( $<45$ vs. $\geq 45$ years), and sex (all $p>0.05$, Mann-Whitney U and Spearman's correlation tests). These results suggest that the evolutionary patterns of SNVs and CNAs are distinct.

\section{Mutational signature shift}

We compared the mutational signatures for mutations specific to or enriched in primary biopsies and mutations 
specific to or enriched in the metastatic tumors, to 21 mutational signatures previously reported in different cancer types (45), for 11 cases (3 cases were excluded from signature analysis due to insufficient number of mutations $[<15]$ to perform this analysis). A shift was observed in the most dominant signature (signature 1a associated with aging) in eight cases. Signature 6 associated with DNA mismatch repair (MMR) deficiency and signature 11 associated with temozolomide were found specific to the metastatic process in five cases. Signature 15 was observed in two cases found specific to primary and metastatic lesions, respectively (Fig. 7 and Supplementary Fig. S5). Mutational signatures were not consistent, as signature shifts did not occur in any particular direction, with observed patterns varying between mutations specific to or enriched in the primary and mutations specific to or enriched in metastasis.

\section{Discussion}

Precision medicine in cancer involves tailoring the best therapy based on specific genomic alterations in the patient's tumor (53). WES analysis of the primary tumor and their matched metastasis can potentially identify novel metastasisassociated mutations and pathways. Although PTC is a typically curable cancer with distant metastasis occurring in less than $6 \%$, it is the most frequent cause of thyroid cancerrelated deaths (6).

Previous studies have attempted to identify reliable markers for predicting the metastatic spreading of PTC $(54,55)$; however, none of these studies were based on simultaneous analysis of paired primary PTCs and their metastases using WES. The comparison analysis with TCGA data (31) showed a median of 24.5 (range 8-62) mutations in our primary cases, while a median of 15 (range 2-87) mutations were found in TCGA data. We found a median of 2 (range 1-5) and 1 (range 1-7) likely pathogenic mutations in our data and TCGA, respectively. With respect to mutations in cancer genes, a median of 2 (range 1-5) and 1 (range 1-6) were found in our primary cases and TCGA, respectively. Known driver gene (BRAF, NRAS, HRAS, and TP53) alterations were observed in $64.3 \%$ in our primary PTC and $71.6 \%$ in TCGA. We present the first WES analysis of genetic changes in primary PTC and their distant metastases.

Striking heterogeneity was observed between biopsies of paired primary tumors and metastases, with a median of only $40.5 \%$ mutations shared between any two biopsies. We also demonstrate that pathogenic mutations affecting MAP kinase pathway genes were present in $57 \%$ of primary tumors and their respective metastases, with only two cases harboring metastasis-restricted MAP kinase mutations (HRAS $S^{Q 61 K}$ $[n=1]$ and $\left.N R A S^{Q 61 K}[n=1]\right)$. However, likely pathogenic mutations in the $A C A C B, C H D 4, E O M E S, F O X E 1, G A T A 2$, RBBP7, SIN3A, TMEM67, TP53, and TYR genes were found only in the metastases that were present at initial diagnosis before therapy, despite a second anatomically distinct diagnostic biopsy of the respective primary tumors. Taken together, these findings suggest that while most of the divergence between metastasis and their corresponding primary PTC tumors is attributed to passenger mutations, a few mutational driver events may play a role in metastasis development and evolution. We have previously reported the role of somatic $T G$ mutations in metastatic PTC tissues (31). de Biase et al. have shown that despite the clinical aggressiveness of distant metastatic PTCs, they tend to have a low mutational load, comparable to nonmetastatic PTCs. They also found frequent mutations in the MED12 and MET genes in metastatic PTCs (54). Other genes reported to play a role in metastatic behavior of PTCs include TERT, ATM, RAS, and RET/PTC (8,56-58). Gandolfi et al. in their study of metastatic PTC found that the THYT1 genetic signature, comprising of duplications in chromosomal regions $1 \mathrm{q}$ and $5 \mathrm{p}$ (harboring the TERT genomic locus), and TERT promoter mutations, was a highly specific marker of distant metastasis in PTCs (59).

We did not observe any specific pattern in terms of the number of mutations or mutational signature in the nine bone metastases or three lung metastases. Neither was there any significant association between the number of mutations and clinicopathological parameters, such as age, stage, or histological subtype. Furthermore, no significant difference was found in the number of mutations in therapy-naive metastases and post-therapy metastases. Interestingly, the lack of correlation among the repertoire of subclonal mutations and CNAs, between primary PTC and metastases, might indicate that somatic mutations and CNAs evolve independently. Several whole-exome studies have identified the increased association between mutational burden and aggressive clinical behavior in several solid tumors.

Previous genomic landscaping of PTC in the TCGA (60) has identified no correlation between mutation burden and any aggressive clinical features such as advanced stage, highgrade tumor, or aggressive histological subtypes. This is in concordance with our previous PTC landscape study (31) where the mutation burden had no effect on any clinical or pathological phenotype, which could be due to the quietness of this tumor and the overall low mutation burden involved in the tumorigenesis.

Importantly, we have identified likely pathogenic metastasisrestricted mutations such as $C H D 4, R B B P 7$, and $S I N 3 A$ that affect DNA methylation and transcriptional repression signaling pathways, which raises the possibility of their involvement in tumor dissemination. The role of epigenetic deregulation in cancer has been well established (61-65); however, with the use of next-generation sequencing technologies, the underlying epigenetic mechanisms pertaining to dysfunction are becoming further evident. Indeed, several exome sequencing studies have demonstrated an important

FIG. 7. Mutational signatures in primary tumor and metastasis. (A) Mutational signatures of the tumor samples analyzed for the mutations enriched in the primary tumor (green) and mutations enriched in the metastatic lesions (orange). The similarity of each mutational signature is annotated according to the signature fraction and is indicated in blue according to the color key. (B) Plots demonstrating the mutational signatures of the mutations enriched in the primary tumor and the metastatic lesion of cases $4,5,6,8,10,12$, and 14. The figure shows each mutational signature according to the 96 substitution classification defined by the substitution classes $(\mathrm{C}>\mathrm{A}, \mathrm{C}>\mathrm{G}, \mathrm{C}>\mathrm{T}, \mathrm{T}>\mathrm{A}, \mathrm{T}>\mathrm{C}$, and $\mathrm{T}>\mathrm{G}$ bins). Color images are available online. 
A

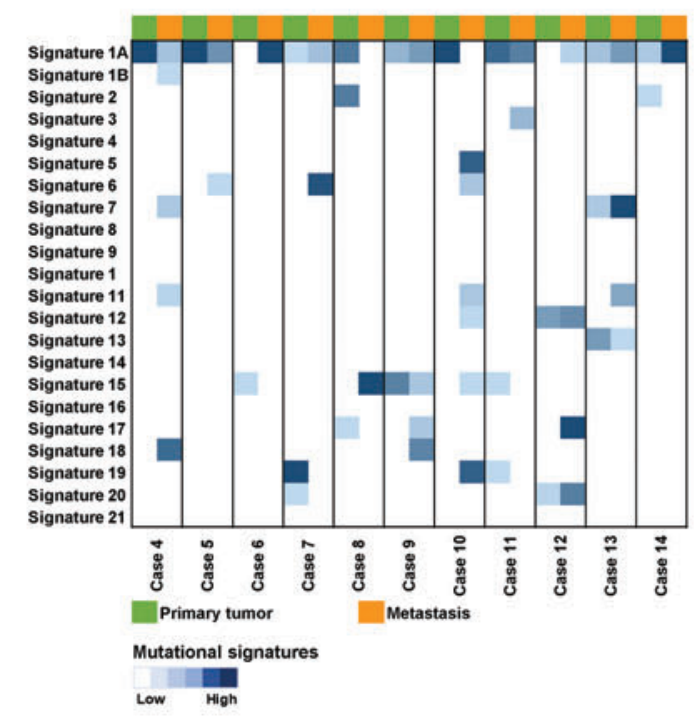

B

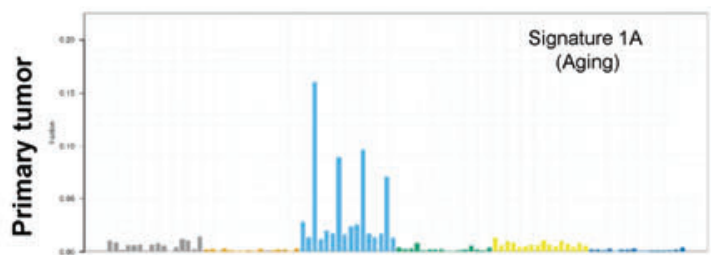

Case 4
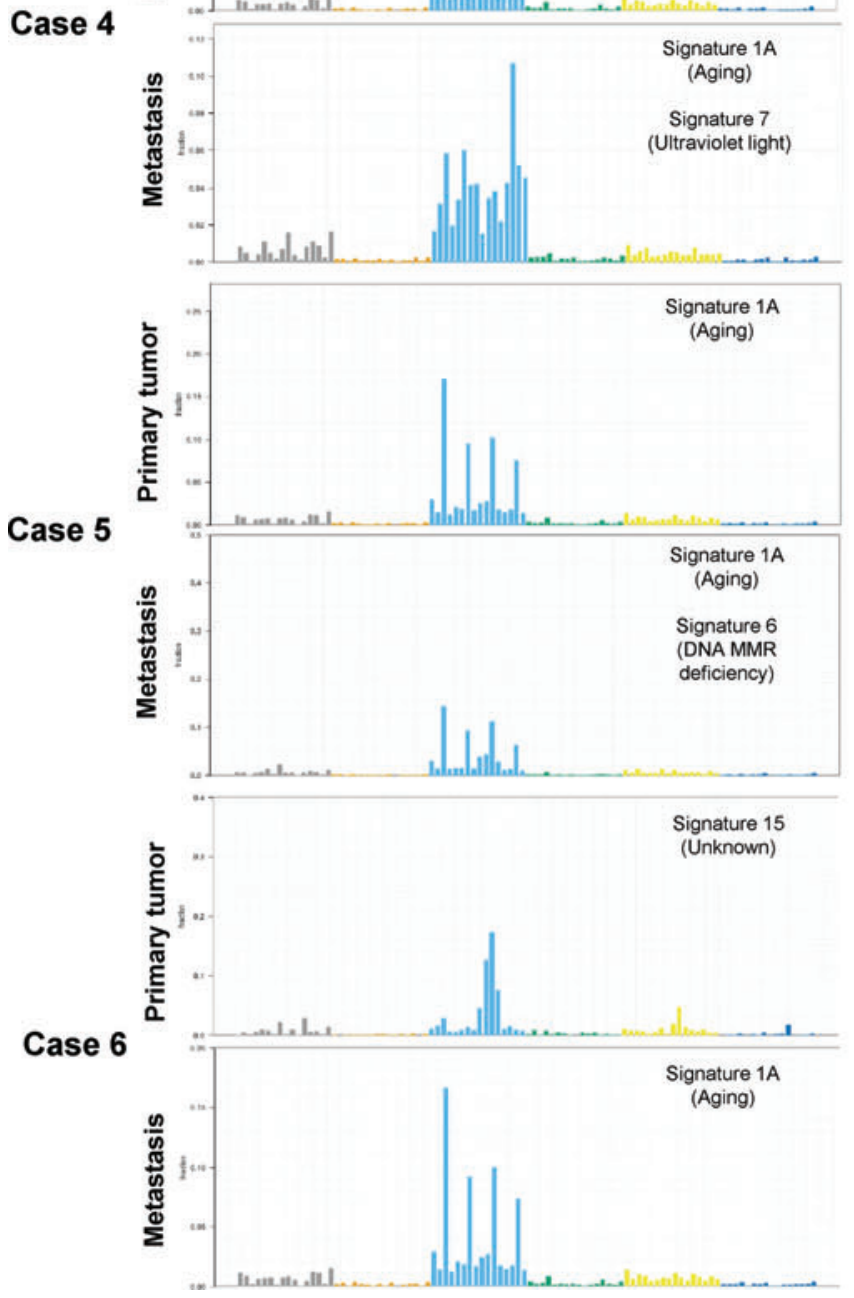
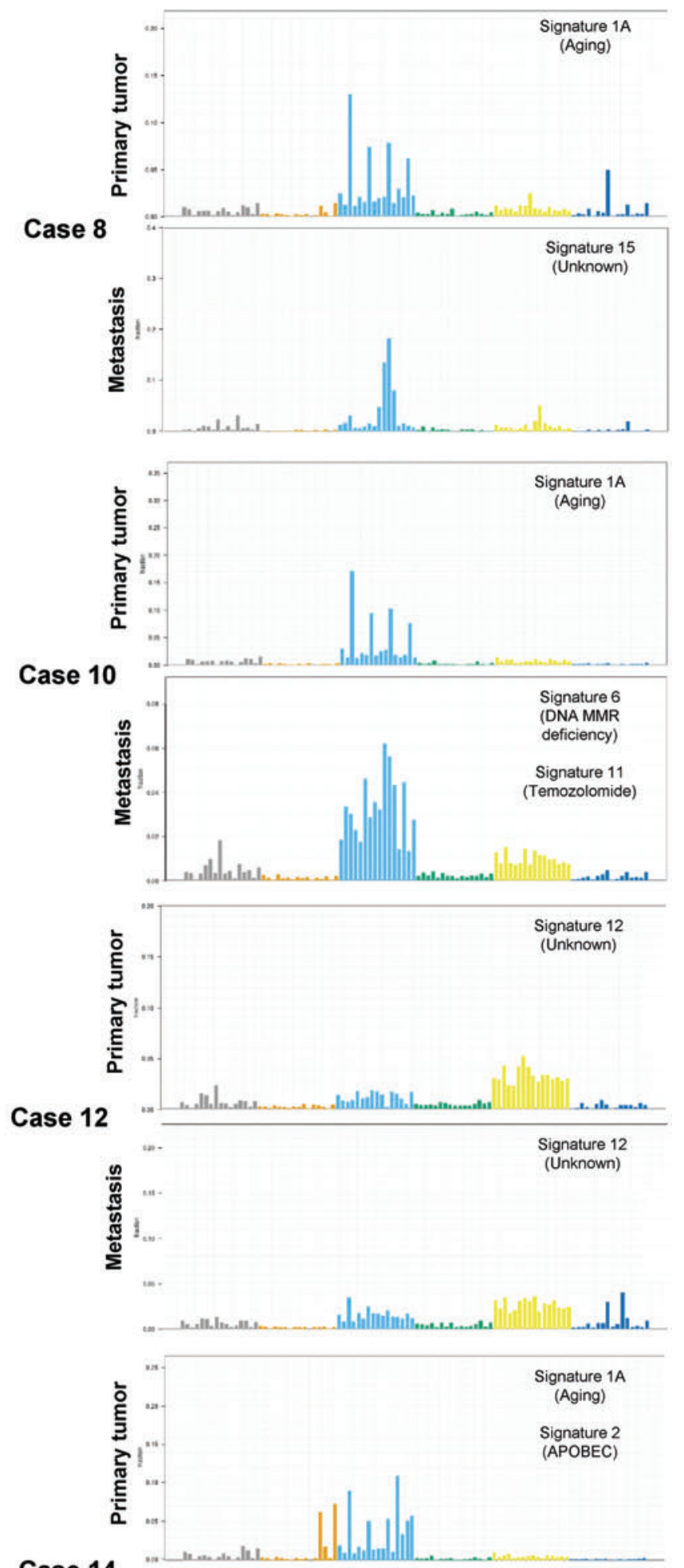

Case 14

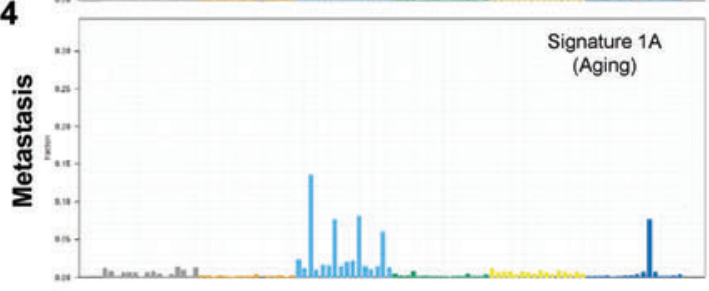

$C>A \quad C>G \quad C>T \quad T>A \quad T>C \quad T>G$ 
role of mutations in genes encoding epigenetic modifiers in many cancers such as renal cell carcinoma and adenoid cystic carcinoma $(66,67)$. Many tumor suppressor genes are silenced through synergistic layers of epigenetic regulation including abnormal DNA hypermethylation of promoter $\mathrm{CpG}$ islands, repressive chromatin modifications, and enhanced nucleosome deposition over transcription start sites (68). Two main forms of chromatin are present in the human genome, either in a condensed transcriptionally inactive form known as heterochromatin or as the transcriptionally active version, that is, euchromatin. Nucleosomes, which are octametric structures composed of two types of histones $(\mathrm{H} 3, \mathrm{H} 4)$ with $147 \mathrm{bp}$ of DNA wrapped around them, are the functional units of chromatin (69). Chromatin remodeling and histone modification have emerged as the main mechanism of gene expression regulation. Transcriptionally active chromatin is associated with hyperacetylation of histones (70), while the chromatin inactive region is enriched in deacetylated histones (71). The acetylation status of histones at specific DNA regulatory sequences depends on the recruitment of histone acetyltransferases or histone deacetylase activities, usually as part of large multiprotein complex of coactivators or corepressors, respectively (71).

Several corepressor complexes, capable of interacting with several transcriptional repressors, have been identified, such as the $\operatorname{Sin} 3$ complex and NuRD complex (containing CHD4, $R B B 4 / 7$, and $M T A-1,-2,-3$ subunits) (72,73). Along with altered epigenomes, often only a few yet potent mutations in selected genes drive tumorigenesis in several neoplasms. While many cancers demonstrate genetic alterations in histone modifiers, some cancers harbor mutations in DNA methylation regulators, whereas others such as glioma and leukemia show a high prevalence of alterations in chromatin modifiers (74). The development of metastatic lesions has not yet been associated with any specific recurrent mutation. This raises the interesting possibility that the perturbation of only a selected number of pathways, such as the repression of select signaling pathways and alteration of DNA methylation, may be involved in metastatic dissemination of a tumor, as suggested by our data.

Mutational signatures in the cancer genome provide indication of mechanisms underlying neoplastic transformation $(75,76)$. According to Alexandrov et al., molecular signature 2 and 5 are common in thyroid cancer (45). However, in our data, these signatures were only found in 2 of the primary PTC and a single metastatic case, with mutational signature 1 and 15 being most common in both primary tumors and their metastases. Furthermore, signature 6 (DNA MMR deficiency) and signature 11 (temozolomide) were observed in metastatic deposits and absent from their primary tissues in five patients. Particularly, mutational signature shifts in defective DNA repair seen in metastatic cases are of high importance. However, our study lacks the presence of multiple samples that could give us a better understanding of this shift between trunk mutations (mutations present in all biopsies of a patient) and non-trunk mutations (mutations present in selected biopsies of a patient). Currently, the genomic evolution of PTC, by using multiple biopsies at different time points to generate phylogenies, is being investigated in our laboratory.

Whether patients presenting with distant metastatic disease should have metastases biopsied to aid in therapeutic interventions is controversial (77). Due to the challenging and invasive nature of many metastatic disease sites, bias is seen in our cohort toward sites with increased level of accessibility.

\section{Conclusions}

As in any cancer, PTC relentlessly exploits a vast mutational repertoire and series of gene pathways to ensure tumor development, survival, and ability to invade distant regions of the body. This leads to considerable variability in interpatient genomic profiles. Recruiting a large prospective cohort of patients with metastatic disease is crucial to map this complexity, along with the incorporation of transcriptional epigenomic and clinical associations. Our data demonstrate that such endeavor would potentially provide insights into the mechanisms of the metastatic process and identify pathways that could represent new therapeutic targets. Finally, our study confirms the interaction between cancer genomics and epigenetics, in support of ongoing developments in new epigenetic therapies.

\section{Acknowledgment}

We thank the patients for their participation.

\section{Authors' Contributions}

T.M. and A.K.S. performed WES, critical data analyses, interpretation of results, and wrote the article. S.S., S.A., Z.Q., and W.N.A. performed DNA extraction, analyzed the data, and carried out statistical analyses. S.K.P., S.S.A., and F.A. contributed samples and analyzed clinical data. F.S.A. and K.S.A. designed, implemented the study, wrote and critically reviewed the article. This is to confirm that all authors read and approved the final article.

\section{Author Disclosure Statement}

No competing financial interests exist.

\section{Funding Information}

This project was conducted by a generous fund from the Saudi Government to the Thyroid Cancer Genome Project as part of the International Cancer Genome Consortium (ICGC).

\section{Supplementary Material}

Supplementary Table S1

Supplementary Table S2

Supplementary Table S3

Supplementary Table S4

Supplementary Table S5

Supplementary Table S6

Supplementary Table S7

Supplementary Figure S1

Supplementary Figure S2

Supplementary Figure S3

Supplementary Figure S4

Supplementary Figure S5 


\section{References}

1. Vecchia C, Malvezzi M, Bosetti C, Garavello W, Bertuccio P, Levi F, Negri E 2015 Thyroid cancer mortality and incidence: a global overview. Int J Cancer 136:2187-2195.

2. Saudi Cancer Registry. Cancer Incidence Report, Saudi Arabia 2015. Riyadh (KSA): Saudi Cancer Registry; 2018. Available at https://nhic.gov.sa/eServices/Documents/E\% 20SCR\%20final\%206\%20NOV.pdf (accessed January 10, 2019).

3. Schneider DF, Chen H 2013 New developments in the diagnosis and treatment of thyroid cancer. CA Cancer J Clin 63:373-394.

4. Song YS, Lim JA, Choi H, Won JK, Moon JH, Cho SW, Lee KE, Park YJ, Yi KH, Park DJ 2016 Prognostic effects of TERT promoter mutations are enhanced by coexistence with BRAF or RAS mutations and strengthen the risk prediction by the ATA or TNM staging system in differentiated thyroid cancer patients. Cancer 122:1370-1379.

5. Fraser S, Go C, Aniss A, Sidhu S, Delbridge L, Learoyd D, Clifton-Bligh R, Tacon L, Tsang V, Robinson B 2016 BRAFV600E mutation is associated with decreased diseasefree survival in papillary thyroid cancer. World J Surg 40: 1618-1624.

6. Nixon IJ, Whitcher MM, Palmer FL, Tuttle RM, Shaha AR, Shah JP, Patel SG, Ganly I 2012 The impact of distant metastases at presentation on prognosis in patients with differentiated carcinoma of the thyroid gland. Thyroid 22:884-889.

7. Goffredo P, Sosa JA, Roman SA 2013 Differentiated thyroid cancer presenting with distant metastases: a population analysis over two decades. World J Surg 37:1599-1605.

8. Vuong HG, Altibi AM, Duong UN, Ngo HT, Pham TQ, Tran HM, Oishi N, Mochizuki K, Nakazawa T, Hassell L 2017 Role of molecular markers to predict distant metastasis in papillary thyroid carcinoma: promising value of TERT promoter mutations and insignificant role of BRAF mutations - a meta-analysis. Tumor Biol 39:1010428317713913.

9. Hay ID, Thompson GB, Grant CS, Bergstralh EJ, Dvorak CE, Gorman CA, Maurer MS, McIver B, Mullan BP, Oberg AL 2002 Papillary thyroid carcinoma managed at the Mayo Clinic during six decades (1940-1999): temporal trends in initial therapy and long-term outcome in 2444 consecutively treated patients. World J Surg 26:879-885.

10. Mazzaferri EL, Kloos RT 2001 Current approaches to primary therapy for papillary and follicular thyroid cancer. J Clin Endocrinol Metab 86:1447-1463.

11. Melmed S, Polonsky K, Larsen P, Kronenberg H 1897 Williams Textbook of Endocrinology, 2011. Saunders Elsevier, Philadelphia.

12. Smith H 1990 Radioiodine-131 in the diagnosis and treatment of metastatic well differentiated thyroid cancer. Endocrinol Metab Clin North Am 19:685-718.

13. Robbins RJ, Schlumberger MJ 2005 The evolving role of ${ }^{131} \mathrm{I}$ for the treatment of differentiated thyroid carcinoma. J Nucl Med 46:28S-37S.

14. Finley DJ, Arora N, Zhu B, Gallagher L, Fahey III TJ 2004 Molecular profiling distinguishes papillary carcinoma from benign thyroid nodules. J Clin Endocrinol Metab 89:32143223.

15. Rodríguez-Rodero S, Fernández AF, Fernández-Morera JL, Castro-Santos P, Bayon GF, Ferrero C, Urdinguio RG, Gonzalez-Marquez R, Suarez C, Fernández-Vega I 2013 DNA methylation signatures identify biologically distinct thyroid cancer subtypes. J Clin Endocrinol Metab 98:28112821.

16. Jamal-Hanjani M, Wilson GA, McGranahan N, Birkbak NJ, Watkins TBK, Veeriah S, Shafi S, Johnson DH, Mitter R, Rosenthal R, Salm M, Horswell S, Escudero M, Matthews N, Rowan A, Chambers T, Moore DA, Turajlic S, Xu H, Lee SM, Forster MD, Ahmad T, Hiley CT, Abbosh C, Falzon M, Borg E, Marafioti T, Lawrence D, Hayward M, Kolvekar S, Panagiotopoulos N, Janes SM, Thakrar R, Ahmed A, Blackhall F, Summers Y, Shah R, Joseph L, Quinn AM, Crosbie PA, Naidu B, Middleton G, Langman G, Trotter S, Nicolson M, Remmen H, Kerr K, Chetty M, Gomersall L, Fennell DA, Nakas A, Rathinam S, Anand G, Khan S, Russell P, Ezhil V, Ismail B, Irvin-Sellers M, Prakash V, Lester JF, Kornaszewska M, Attanoos R, Adams H, Davies H, Dentro S, Taniere P, O'Sullivan B, Lowe HL, Hartley JA, Iles N, Bell H, Ngai Y, Shaw JA, Herrero J, Szallasi Z, Schwarz RF, Stewart A, Quezada SA, Le Quesne J, Van Loo P, Dive C, Hackshaw A, Swanton C, Consortium TR 2017 Tracking the evolution of non-smallcell lung cancer. N Engl J Med 376:2109-2121.

17. Ng CK, Bidard F-C, Piscuoglio S, Geyer FC, Lim RS, De Bruijn I, Shen R, Pareja F, Berman SH, Wang L 2017 Genetic heterogeneity in therapy-naïve synchronous primary breast cancers and their metastases. Clin Cancer Res 23:4402-4415.

18. Yates LR, Knappskog S, Wedge D, Farmery JH, Gonzalez S, Martincorena I, Alexandrov LB, Van Loo P, Haugland HK, Lilleng PK 2017 Genomic evolution of breast cancer metastasis and relapse. Cancer Cell 32:169-184. e167.

19. Bertucci F, Finetti P, Guille A, Adélaïde J, Garnier S, Carbuccia N, Monneur A, Charafe-Jauffret E, Goncalves A, Viens P 2016 Comparative genomic analysis of primary tumors and metastases in breast cancer. Oncotarget 7: 27208.

20. Schrijver WA, Jiwa LS, van Diest PJ, Moelans CB 2015 Promoter hypermethylation profiling of distant breast cancer metastases. Breast Cancer Res Treat 151:41-55.

21. Gibson WJ, Hoivik EA, Halle MK, Taylor-Weiner A, Cherniack AD, Berg A, Holst F, Zack TI, Werner HM, Staby KM 2016 The genomic landscape and evolution of endometrial carcinoma progression and abdominopelvic metastasis. Nat Genet 48:848.

22. Faltas B, Beltran H, Prandi D, Eng K, Pauli C, Robinson BD, Mosquera JM, Nanus DM, Tagawa ST, Elemento O 2015 Whole exome sequencing to reveal chemotherapydriven evolution of platinum-resistant metastatic urothelial cancer. J Clin Oncol 33(15_suppl):4513-4513.

23. Wei Q, Ye Z, Zhong X, Li L, Wang C, Myers R, Palazzo J, Fortuna D, Yan A, Waldman S 2017 Multiregion wholeexome sequencing of matched primary and metastatic tumors revealed genomic heterogeneity and suggested polyclonal seeding in colorectal cancer metastasis. Ann Oncol 28:2135-2141.

24. Ouyang L, Lee J, Park C-K, Mao M, Shi Y, Gong Z, Zheng H, Li Y, Zhao Y, Wang G 2014 Whole-genome sequencing of matched primary and metastatic hepatocellular carcinomas. BMC Med Genomics 7:2.

25. Goswami RS, Patel KP, Singh RR, Meric-Bernstam F, Kopetz ES, Subbiah V, Alvarez RH, Davies MA, Jabbar KJ, Roy-Chowdhuri S 2015 Hotspot mutation panel testing reveals clonal evolution in a study of 265 paired primary and metastatic tumors. Clin Cancer Res. 
26. Li H, Durbin R 2010 Fast and accurate long-read alignment with Burrows-Wheeler transform. Bioinformatics 26:589595.

27. McKenna A, Hanna M, Banks E, Sivachenko A, Cibulskis K, Kernytsky A, Garimella K, Altshuler D, Gabriel S, Daly M 2010 The genome analysis toolkit: a MapReduce framework for analyzing next-generation DNA sequencing data. Genome Res 20:1297-1303.

28. Cibulskis K, Lawrence MS, Carter SL, Sivachenko A, Jaffe D, Sougnez C, Gabriel S, Meyerson M, Lander ES, Getz G 2013 Sensitive detection of somatic point mutations in impure and heterogeneous cancer samples. Nat Biotechnol 31:213.

29. Koboldt DC, Zhang Q, Larson DE, Shen D, McLellan MD, Lin L, Miller CA, Mardis ER, Ding L, Wilson RK 2012 VarScan 2: somatic mutation and copy number alteration discovery in cancer by exome sequencing. Genome Res 22: 568-576.

30. Wang K, Li M, Hakonarson H 2010 ANNOVAR: functional annotation of genetic variants from high-throughput sequencing data. Nucleic Acids Res 38:e164.

31. Siraj AK, Masoodi T, Bu R, Beg S, Al-Sobhi SS, Al-Dayel F, Al-Dawish M, Alkuraya FS, Al-Kuraya KS 2016 Genomic profiling of thyroid cancer reveals a role for thyroglobulin in metastasis. Am J Hum Genet 98:1170-1180.

32. Shen R, Seshan VE 2016 FACETS: allele-specific copy number and clonal heterogeneity analysis tool for highthroughput DNA sequencing. Nucleic Acids Res 44:e131.

33. Carter SL, Cibulskis K, Helman E, McKenna A, Shen H, Zack T, Laird PW, Onofrio RC, Winckler W, Weir BA 2012 Absolute quantification of somatic DNA alterations in human cancer. Nat Biotechnol 30:413.

34. Schwarz JM, Rödelsperger C, Schuelke M, Seelow D 2010 MutationTaster evaluates disease-causing potential of sequence alterations. Nat Methods 7:575.

35. Carter H, Chen S, Isik L, Tyekucheva S, Velculescu VE, Kinzler KW, Vogelstein B, Karchin R 2009 Cancer-specific high-throughput annotation of somatic mutations: computational prediction of driver missense mutations. Cancer Res 69:6660-6667.

36. Shihab HA, Gough J, Cooper DN, Stenson PD, Barker GL, Edwards KJ, Day IN, Gaunt TR 2013 Predicting the functional, molecular, and phenotypic consequences of amino acid substitutions using hidden Markov models. Hum Mutat 34:57-65.

37. Choi Y, Sims GE, Murphy S, Miller JR, Chan AP 2012 Predicting the functional effect of amino acid substitutions and indels. PLoS One 7:e46688.

38. Dang VT, Kassahn KS, Marcos AE, Ragan MA 2008 Identification of human haploinsufficient genes and their genomic proximity to segmental duplications. Eur J Hum Genet 16:1350.

39. Chang MT, Asthana S, Gao SP, Lee BH, Chapman JS, Kandoth C, Gao J, Socci ND, Solit DB, Olshen AB 2016 Identifying recurrent mutations in cancer reveals widespread lineage diversity and mutational specificity. Nat Biotechnol 34:155.

40. Futreal PA, Coin L, Marshall M, Down T, Hubbard T, Wooster R, Rahman N, Stratton MR 2004 A census of human cancer genes. Nat Rev Cancer 4:177.

41. Kandoth C, McLellan MD, Vandin F, Ye K, Niu B, Lu C, Xie M, Zhang Q, McMichael JF, Wyczalkowski MA 2013 Mutational landscape and significance across 12 major cancer types. Nature 502:333.
42. Lawrence MS, Stojanov P, Mermel CH, Robinson JT, Garraway LA, Golub TR, Meyerson M, Gabriel SB, Lander ES, Getz G 2014 Discovery and saturation analysis of cancer genes across 21 tumour types. Nature 505:495.

43. Reimand J, Arak T, Adler P, Kolberg L, Reisberg S, Peterson H, Vilo J $2016 \mathrm{~g}$ :Profiler-a web server for functional interpretation of gene lists (2016 update). Nucleic Acids Res 44:W83-W89.

44. Rosenthal R, McGranahan N, Herrero J, Taylor BS, Swanton C 2016 DeconstructSigs: delineating mutational processes in single tumors distinguishes DNA repair deficiencies and patterns of carcinoma evolution. Genome Biol 17:31.

45. Alexandrov LB, Nik-Zainal S, Wedge DC, Aparicio SA, Behjati S, Biankin AV, Bignell GR, Bolli N, Borg A, Børresen-Dale A-L 2013 Signatures of mutational processes in human cancer. Nature 500:415.

46. de Biase D, Gandolfi G, Ragazzi M, Eszlinger M, Sancisi V, Gugnoni M, Visani M, Pession A, Casadei G, Durante C, Costante G, Bruno R, Torlontano M, Paschke R, Filetti S, Piana S, Frasoldati A, Tallini G, Ciarrocchi A 2015 TERT promoter mutations in papillary thyroid microcarcinomas. Thyroid 25:1013-1019.

47. Melo M, da Rocha AG, Vinagre J, Batista R, Peixoto J, Tavares C, Celestino R, Almeida A, Salgado C, Eloy C, Castro P, Prazeres H, Lima J, Amaro T, Lobo C, Martins MJ, Moura M, Cavaco B, Leite V, Cameselle-Teijeiro JM, Carrilho F, Carvalheiro M, Maximo V, Sobrinho-Simoes M, Soares P 2014 TERT promoter mutations are a major indicator of poor outcome in differentiated thyroid carcinomas. J Clin Endocrinol Metab 99:E754-E765.

48. Bu R, Siraj AK, Divya SP, Kong Y, Parvathareddy SK, AlRasheed M, Al-Obaisi KAS, Victoria IG, Al-Sobhi SS, AlDawish M, Al-Dayel F, Al-Kuraya KS 2018 Telomerase reverse transcriptase mutations are independent predictor of disease-free survival in Middle Eastern papillary thyroid cancer. Int J Cancer 142:2028-2039.

49. Liu R, Xing M 2016 TERT promoter mutations in thyroid cancer. Endocr Relat Cancer 23:R143-R155.

50. Yates LR, Gerstung M, Knappskog S, Desmedt C, Gundem G, Van Loo P, Aas T, Alexandrov LB, Larsimont D, Davies H 2015 Subclonal diversification of primary breast cancer revealed by multiregion sequencing. Nat Med 21:751.

51. Murugaesu N, Wilson GA, Birkbak NJ, Watkins TB, McGranahan N, Kumar S, Abbassi-Ghadi N, Salm M, Mitter R, Horswell S 2015 Tracking the genomic evolution of esophageal adenocarcinoma through neoadjuvant chemotherapy. Cancer Discov 5:821-831.

52. Wang Y, Waters J, Leung ML, Unruh A, Roh W, Shi X, Chen K, Scheet P, Vattathil S, Liang H, Multani A, Zhang H, Zhao R, Michor F, Meric-Bernstam F, Navin NE 2014 Clonal evolution in breast cancer revealed by single nucleus genome sequencing. Nature 512:155-160.

53. Beltran H, Eng K, Mosquera JM, Sigaras A, Romanel A, Rennert H, Kossai M, Pauli C, Faltas B, Fontugne J 2015 Whole-exome sequencing of metastatic cancer and biomarkers of treatment response. JAMA Oncol 1:466-474.

54. de Biase D, Torricelli F, Ragazzi M, Donati B, Khun E, Visani M, Acquaviva G, Pession A, Tallini G, Piana S, Ciarrocchi A 2018 Not the same thing: metastatic PTCs have a different background than ATCs. Endocr Connect pii: EC-18-0386.R2.

55. Xing M, Alzahrani AS, Carson KA, Viola D, Elisei R, Bendlova B, Yip L, Mian C, Vianello F, Tuttle RM, Ro- 
benshtok E, Fagin JA, Puxeddu E, Fugazzola L, Czarniecka A, Jarzab B, O'Neill CJ, Sywak MS, Lam AK, RiescoEizaguirre G, Santisteban P, Nakayama H, Tufano RP, Pai SI, Zeiger MA, Westra WH, Clark DP, Clifton-Bligh R, Sidransky D, Ladenson PW, Sykorova V 2013 Association between $\mathrm{BRAF}^{\mathrm{V} 600 \mathrm{E}}$ mutation and mortality in patients with papillary thyroid cancer. JAMA 309:1493-1501.

56. Gu Y, Liu X, Yu Y, Shi J, Ai L, Sun H, Kanu JS, Wang C, Liu Y 2014 Association of ATM gene polymorphism with PTC metastasis in female patients. Int J Endocrinol 2014: 370825.

57. Gandolfi G, Ragazzi M, Frasoldati A, Piana S, Ciarrocchi A, Sancisi V 2015 TERT promoter mutations are associated with distant metastases in papillary thyroid carcinoma. Eur J Endocrinol 172:403-413.

58. Xu B, Tuttle RM, Sabra MM, Ganly I, Ghossein R 2017 Primary thyroid carcinoma with low-risk histology and distant metastases: clinicopathologic and molecular characteristics. Thyroid 27:632-640.

59. Gandolfi G, Ragazzi M, de Biase D, Visani M, Zanetti E, Torricelli F, Sancisi V, Gugnoni M, Manzotti G, Braglia L 2018 Genome-wide profiling identifies the THYT1 signature as a distinctive feature of widely metastatic papillary thyroid carcinomas. Oncotarget 9:1813.

60. Cancer Genome Atlas Research N 2014 Integrated genomic characterization of papillary thyroid carcinoma. Cell 159: 676-690.

61. Feinberg AP, Vogelstein B 1983 Hypomethylation distinguishes genes of some human cancers from their normal counterparts. Nature 301:89.

62. Teodoridis JM, Strathdee G, Brown R 2004 Epigenetic silencing mediated by $\mathrm{CpG}$ island methylation: potential as a therapeutic target and as a biomarker. Drug Resist Updat 7:267-278

63. Boyes J, Byfield P, Nakatani Y, Ogryzko V 1998 Regulation of activity of the transcription factor GATA-1 by acetylation. Nature 396:594.

64. Luo J, Li M, Tang Y, Laszkowska M, Roeder RG, Gu W 2004 Acetylation of p53 augments its site-specific DNA binding both in vitro and in vivo. Proc Natl Acad Sci U S A 101:2259-2264.

65. Hansen KH, Bracken AP, Pasini D, Dietrich N, Gehani SS, Monrad A, Rappsilber J, Lerdrup M, Helin K 2008 A model for transmission of the H3K27me3 epigenetic mark. Nat Cell Biol 10:1291.

66. Dalgliesh GL, Furge K, Greenman C, Chen L, Bignell G, Butler A, Davies H, Edkins S, Hardy C, Latimer C 2010 Systematic sequencing of renal carcinoma reveals inactivation of histone modifying genes. Nature 463:360.

67. Ho AS, Kannan K, Roy DM, Morris LG, Ganly I, Katabi N, Ramaswami D, Walsh LA, Eng S, Huse JT 2013 The mu- tational landscape of adenoid cystic carcinoma. Nat Genet 45:791.

68. Cai Y, Geutjes E-J, De Lint K, Roepman P, Bruurs L, Yu L, Wang W, Van Blijswijk J, Mohammad H, De Rink I 2014 The NuRD complex cooperates with DNMTs to maintain silencing of key colorectal tumor suppressor genes. Oncogene 33: 2157.

69. Margueron R, Reinberg D 2010 Chromatin structure and the inheritance of epigenetic information. Nat Rev Genet 11:285.

70. Strahl BD, Allis CD 2000 The language of covalent histone modifications. Nature 403:41.

71. Peinado H, Ballestar E, Esteller M, Cano A 2004 Snail mediates E-cadherin repression by the recruitment of the Sin3A/histone deacetylase 1 (HDAC1)/HDAC2 complex. Mol Cell Biol 24:306-319.

72. Ahringer J $2000 \mathrm{NuRD}$ and SIN3: histone deacetylase complexes in development. Trends Genet 16:351-356.

73. Jepsen K, Rosenfeld MG 2002 Biological roles and mechanistic actions of co-repressor complexes. J Cell Sci 115:689-698.

74. Roy DM, Walsh LA, Chan TA 2014 Driver mutations of cancer epigenomes. Protein Cell 5:265-296.

75. Alexandrov LB 2015 Understanding the origins of human cancer. Science 350:1175-1177.

76. Helleday T, Eshtad S, Nik-Zainal S 2014 Mechanisms underlying mutational signatures in human cancers. Nat Rev Genet 15:585.

77. Arnedos M, Vicier C, Loi S, Lefebvre C, Michiels S, Bonnefoi H, Andre F 2015 Precision medicine for metastatic breast cancer-limitations and solutions. Nat Rev Clin Oncol 12:693.

Address correspondence to:

Khawla S. Al-Kuraya, MD

Human Cancer Genomic Research

King Faisal Specialist Hospital and Research Center

MBC\#98-16, PO Box 3354

Riyadh 11211

Saudi Arabia

E-mail: kkuraya@kfshrc.edu.sa

Fowzan S. Alkuraya, MD

Department of Genetics

King Faisal Specialist Hospital and Research Centre

MBC-03, PO Box 3354

Riyadh 11211

Saudi Arabia

E-mail: falkuraya@kfshrc.edu.sa 